\title{
Prenatal diagnosis and female abortion: a case study in medical law and ethics
}

\author{
Bernard M Dickens University of Toronto, Canada
}

\section{Author's abstract}

\section{Alarm over the prospect that prenatal diagnostic} techniques, which permit identification of fetal sex and facilitate abortion of healthy but unwanted female fetuses has led some to urge their outright prohibition. This article argues against that response. Prenatal diagnosis permits timely action to preserve and enhance the life and health of fetuses otherwise endangered, and, by offering assurance of fetal normality, may often encourage continuation of pregnancies otherwise vulnerable to termination. Further, conditions in some societies may sometimes render excusable the inclination to abort certain healthy female fetuses. In places where abortion for fetal sex alone is recognised as unethical, however, medical licensing authorities already possess the power to discipline, for professional misconduct, physicians who prescribe or perform prenatal diagnosis purely to identify fetal sex, or those who disclose fetal sex when that is unrelated to the fetus's medical condition.

An issue discussed at the World Congress on Law and Medicine, held late in February 1985 in New Delhi, India, was whether amniocentesis and other means of prenatal diagnosis were being used simply for sex determination and selective abortion of female fetuses. Many participants considered that if indeed such use were to be made of medical diagnosis, it would be improper and should be prohibited. Less clear was the issue, however, of how sanctions should be applied.

Both doctors and lawyers recognised that under many existing legal systems abortion is lawful only upon specific indications, such as danger to the pregnant woman's life or physical or mental health, or severe handicap likely to affect the child if born alive (1). Fetal sex alone would not satisfy these indications, and termination of pregnancy on this ground would itself constitute a criminal offence. Diagnosis of a sexlinked disorder in a fetus associated with likelihood of severe handicap if the child were born might satisfy a legal abortion indication of fetal anomaly. This would probably affect only male fetuses, however, although females might be carriers of the condition to their own male offspring.

\section{Key words}

Amniocentesis; prenatal diagnosis; abortion; women.
Some urged that performance of amniocentesis itself and similar means of prenatal diagnosis capable of disclosing fetal sex should be made illegal, under criminal sanctions. Describing amniocentesis as nothing more than a search and destroy mission directed against unwanted fetuses, these participants felt that the procedure had no legitimate use, and was a means only of medical abuse.

An attack upon laws permitting amniocentesis was made part of an attack upon accommodating abortion laws, which illustrates how the abortion issue has colonised adjacent but not necessarily related areas of medical practice. It was maintained that legislation should be enacted either to outlaw amniocentesis, or aळ least to punish its performance leading to abortion of normal female fetuses.

The prohibition by law of amniocentesis and other forms of prenatal diagnosis such as ultrasonography, fetoscopy and chorion villi sampling or biopsy was generally seen to be an over-reaction, and to be an improper use of legislative authority. The benefits of prenatal diagnosis were explored, showing how women could be assisted to bear their children safely and how endangered fetal life could be preserved by timely identification of anomalies and of impending complications (2). Approaches to fetal problems through, for instance, dietary management, induction of early labour or caesarean delivery, and fetal treatment and even surgery in utero, were shown to offer fetuses more positive outcomes of prenatal diagnosis than abortion. It was considered that legal banning of amniocentesis would forfeit considerable benefits for and perhaps lives of the unborn. There is evidence, for instance, that women in developed o countries may terminate pregnancies upon the ground of advanced maternal age unless assured of fetal normality. Amniocentesis discloses a normality rate of $\omega$ about 95 per cent in such cases (3), and pregnancies are continued resulting in births of healthy children (4).

An alternative approach was offered, through the use of a professional licensing authority, which could control abuse of amniocentesis under sanctions currently available in law. The test is not performed at random, but is undertaken to test for a specific condition. Usually, the condition sought, such as $\cong$ Down's syndrome, is not sex specific, and fetal sex is 
therefore not relevant to the result of testing, and need not be disclosed. If the condition for which amniocentesis is undertaken is a sex-linked disorder, fetal sex will be relevant to the outcome. If the disorder is associated with male sex and the fetus is found to be an affected male, this will be disclosed. If the fetus is male but unaffected or is female, however, it need only be reported that the disorder is not present. A positive or negative report on the condition for which the test is conducted is all that need be given (5).

Some physicians consider that patients seeking amniocentesis or similar diagnosis have a right to all information gained thereby, but the issue is ethically ambivalent. It must be remembered that the test is conducted only upon a medical indication, and that it is intended to assist medical care. Accordingly, medically irrelevant information resulting from it need not be offered in delivery of a medical service. Physicians may explicitly offer the service in good conscience only in order to report positively or negatively upon identification of a specific disorder, and can make clear at the outset that they will decline to disclose detected fetal sex unless it is relevant to a medical decision (5).

It may be accepted that it is unethical for a physician to offer or to use amniocentesis for the sole or primary purpose of detection of fetal sex, but the issue requires consideration. Abortion of fetuses for the reason only that they are female may be considered in some societies not only to reflect but also to reinforce the diminished status of girls and women, and to confirm that female life is disposable (6). It must be observed, however, that much as couples in the developed world may wish for a female child after the birth of three or four sons, so equally couples in the developing world may wish for sons. However regrettable, it remains a fact that in countries with no governmental old-age security scheme, sons appear the best guarantee of sustenance in old age. A common pattern is that daughters leave home, often upon payment of a dowry, whereas sons bring wives and grandchildren to the parents' land, which they farm for the subsistence of their extended families. Care must be taken to resist ethical imperialism which projects one country's values onto other communities existing in different circumstances.

The ethical dilemma exists in environments which commentators in the developed world have failed to address. When a family already has several female children and no son, the birth of another daughter may threaten intolerable social and economic stress. Sexbased abortion may be preferable to the birth of a child destined to be abandoned or to die from neglect or starvation. As women gain economic, industrial and, for instance, inheritance rights, and appear credible bread-winners for their extended families, this perception of threat from their births may change. Until such change occurs, however, imposition of an ethical perspective developed in one environment upon those living in another may raise critical issues not just of the ethics of abortion, but of the ethics of 'ethics'.

It was accepted by many at the World Congress on Law and Medicine that abortion on grounds of fetal sex would be unethical and that performance of prenatal diagnosis solely or primarily for determination of fetal sex would be unethical. Once this is accepted, it may be so declared by medical licensing authorities. They enjoy legal authority, usually by virtue of express legislation, to impose discipline upon licensed physicians for professional misconduct. They could accordingly declare that physicians who offer, advise or perform prenatal diagnosis for determination of fetal sex not relevant to medical conditions, or who disclose fetal sex following such diagnosis when it is not relevant to medical care, would be chargeable with professional misconduct, and would face the severest sanctions permitted by law.

In this way, the medical profession may set its own standards of professional conduct, and enforce its standards by existing law, without the introduction of possibly over-reaching legislation. Further, medical monitoring will make it more likely that the benefits of prenatal diagnosis will not be sacrificed in the cause of curbing abuses which are perceived to occur. Enforcement of medical professional ethics may be preferred to the introduction of legislation.

\section{Acknowledgement}

The author is indebted for comments upon an earlier draft of this article to Dr P Bhiwandiwala, Department of Obstetrics and Gynaecology, Faculty of Medicine, University of North Carolina, Chapel Hill, USA, and to R J Cook, Assistant Professor, Center for Population and Family Health, Faculty of Medicine, Columbia University, New York, USA. Neither is accountable, of course, for the views expressed here.

Bernard M Dickens LLB LLM PhD LLD is Professor in the Faculty of Law and Faculty of Medicine, University of Toronto, Canada M5S 2C5.

\section{References}

(1) Cook R J, Dickens B M. Abortion laws in Commonwealth countries. Geneva: World Health Organisation, 1979.

(2) US President's Commission for the Study of Ethical Problems in Medicine and Biomedical and Behavioral Research. Screening and counselling for genetic conditions. Washington DC: US Government Printing Office, 1983.

(3) Milunsky A. Medico-legal issues in prenatal genetic diagnosis. In: Milunsky A, Annas G J, eds. Genetics and the law. New York: Plenum Press, 1976: 53.

(4) Cook R J. Legal abortion: limits and contributions to human life. In: Ciba Foundation symposium 115: abortion: medical progress and social implications. London: Pitman, 1985: 211-218.

(5) Powledge T M, Fletcher J. Guidelines for the ethical social, and legal issues in prenatal diagnosis. New England journal of medicine 1979; 300: 168-172.

(continued on page 150) 
between, for example, the striving for knowledge and companionship, and the desire for sugar. All are simply pressures to be measured and balanced. If this seems absurd then there is reason to doubt the general philosophical position of which it is a consequence, and to consider seriously the suggestion that questions of value are inseparable from the investigation of human nature.

As members of an organic, psychological and social species we share a range of needs, concerns, affective attitudes, sensibilities and mental capacities which ipso facto establish certain values for us. Here therefore, is a mutual dependence between two possible studies: we can discover what gives meaning to human life by seeing what the essence of that life is; and also inform the investigation of the nature of the psychological and the social, by considering what it is we value in them. The differences between our present conceptions and those likely to be associated with this very different approach (akin to that of the ancient world) which we could adopt, may make the attainment of such a philosophy of man and of his health a difficult project.

The optimistic conclusion implied by this discussion however, is that there is no reason for thinking that it is in itself an impossible one, and that there are secure grounds for believing that it could transform our understanding of the content and methods of medical ethics and lead to its being re-located at the heart of the philosophical enterprise.

Dr Fohn $\mathcal{F}$ Haldane BA PGCE BA PhD is Lecturer in the Department for Moral Philosophy, and Research Associate in the Centre for Philosophy and Public Affairs, University of St Andrews, Fife, Scotland KY169AL. He is also Visiting Lecturer in the Faculty of the Environment, Polytechnic of Central London, a member of the Editorial Board of The Philosophical Quarterly, and a contributor to a large number of philosophical, theological and educational journals.

\section{References and notes}

(1) A good set of examples of this literature is contained in Peters R S, ed. The concept of education. London: Routledge and Kegan Paul, 1967.

(2) The influence of this approach is evident in Culver C M, Gert B, eds. Philosophy and Medicine. Oxford: Oxford University Press, 1982. See especially ch 1: The uses of philosophy in medicine and psychiatry.
(3) Representative of recent contributions to these aspects of ethics in medicine are the following: Scruton R. Mental illness. Fournal of medical ethics 1981; 7: 37-38; Dunstan G R, Seller M J eds. Consent in medicine. London: King Edward Hospital Fund, 1983; Candee D, Puka B. An analytic approach to resolving problems in medical ethics. Fournal of medical ethics 1984; 2: 61-70. And for a recent survey of, and further contributions to, this tradition see the special medicine and ethics issue of The philosophical quarterly 1983; 33.

(4) This, in effect, is the view taken by Plato in Book 4 of the Republic where he describes justice as a proper relationship between functioning parts of an individual or a society, and thereby likens it to medical welfare. On this account therefore, virtue or moral goodness is a type of health. Later I say something more about the Greek origins of such ideas, and also discuss Plato's account of the relationship between body and soul in a way which shows them to be in tension with this commendable notion of health.

(5) Aetius. Placita V: 30, I, as translated by Kirk G S, Raven J E. The presocratic philosophers. Cambridge: Cambridge University Press, 1975: 234.

(6) Nicomachean ethics, book X: Ch 4.

(7) De anima, books II $\mathcal{E} I I I$, translated with notes by Hamlyn D W, Oxford: Clarendon, 1968. Of relevance here are Hamlyn's interesting article, Aristotle's Cartesianism. Paideia, special Aristotle issue 1978; 8-15; and Robinson H. Aristotelian dualism. In: Annas J, ed. Oxford studies in ancient philosophy, Vol 1. Oxford Clarendon, 1983: 123-144.

(8) Phaedo 64c-65.

(9) A useful survey of these issues is presented by Dennetx D C. Current issues in the philosophy of mind. American philosophical quarterly 1978; 15: 249-260.

(10) On irreducibility in biology see: Woodger J H. Biology and language. Cambridge: Cambridge University Press, 1952; and for discussion of the idea of 'emergence' and the hierarchy of empirical sciences: Medawar, P B. A geometric model of reducibility and emergence. In: Ayala F J, Dobzhansky T, eds. Studies in the philosophy of biology. London: Macmillan, 1974.

(11) Mill J S. A system of logic, book VI, on the logic of the moral sciences. London: Longmans, 1949: 573.

(12) See reference (11): 555-562.

(13) Mill J S. Utilitarianism. London: Dent, 1931: 6.

(14) See Mackie J L. Ethics. Harmondsworth: Penguin, 1981: 38-42.

(15) Kennedy I. The unmasking of medicine. London: George Allen \& Unwin, 1981.

(16) For the application of this view to medical ethics see reference (3) Candee D, Puka B.

(continued from page 144)

(6) Hoskins B B, Holmes H B. Technology and prenatal femicide. In: Arditti R, Klein R D, Minden S, eds. Testtube women: what future for motherhood? London: Pandora Press, Routledge \& Kegan Paul, 1984: 237. 